\title{
THE DEVELOPMENT OF BLAST-FURNACE
}

\section{BLOWING-ENGINES.}

By Mr. DAVID E. ROBERTS, Member, of CardifF.

Historical.-In the early days of machines for blowing air, hollow reeds, bamboos, the trompe, and other primitive means had their important uses. In tracing, however, a brief history of the development of such machines, probably the goat-skin will make the best starting-point. Among eastern nations ages ago the goat-skin, inflated by hand and compressed by the feet, was used for blowing purposes, and in the more backward districts it is still to be found. The addition of two boards made a distinct improvement, and brought about the bellows. This must be looked upon as the first really practical form of blowing-machine; and, driven by a water-wheel, fitted with an inlet and ontlet valve, as shown in Fig. 1 (page 376), it was used in the early days of blast-furnaces. In actual operation its leather sides would be subject to continual repair, and possibly that trouble brought about the next step in advance, shown in Fig. 2 (page 376), in which the bottom board of the bellows is made to work as a piston still carrying the inlet-valve.

In this early type both the piston and the inverted tub were made square and of timber, the latter being built up of staves. This is really only a very small step from the bellows, and following 
upon it came the idea of making the piston operative on the "down" stroke, and consequently the closing of the bottom end of the tub, and the removal of the inlet-valve to the cover. A little later the piston and tub were made of cast-iron and cylindrical, and to this latter atage of development the blowing-machine had reached towards the end of the eighteenth century.

Valves.-The old leather flap-valres, strengthened by iron straps and closing against a grid-iron face, have retained their identity from the early days of the bellows through all the changes,

Fra. 1.

Early Bellows Blowing-machine.

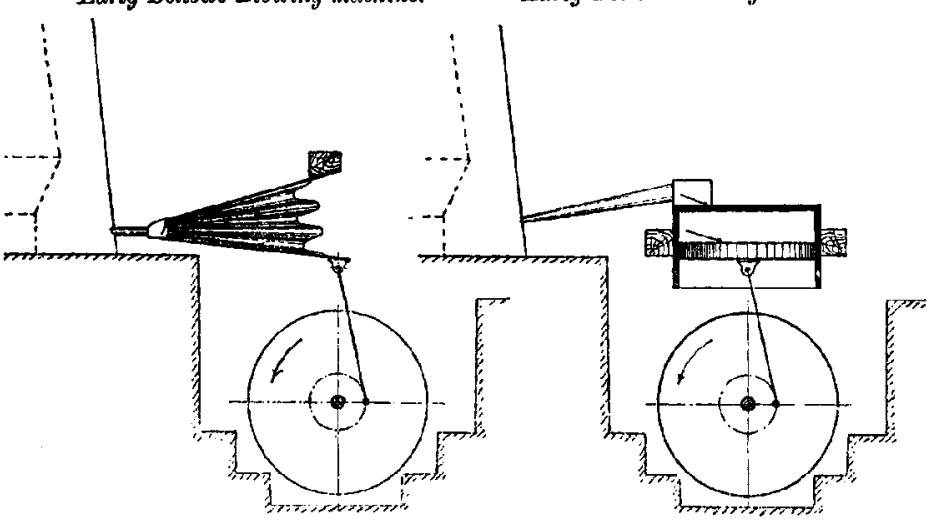

Fig. 2.

Early Piston Blowing-machine.

and are to be found today in many of the older engines. Their action is entirely automatic, and although attempts have beon made both by springs and counter-weights to close these valves more accurately at the dead points, they have been somewhat of a preventative to high speeds and high pressures.

It was recognised as early as the year 1850, by Mr. Archibald Slate, that to enable a blowing-engine to run at a fairiy high speed without serious shocks the valves had to be positively controlled, opened, and closed at the exact instant necessary. Mr. Slate first of all experimented with an ordinary plain slide-valve, and achieved 
Fra. 3.

Bloving Cylinder fitted with Kennedy-Reynolds Valve-Gear.

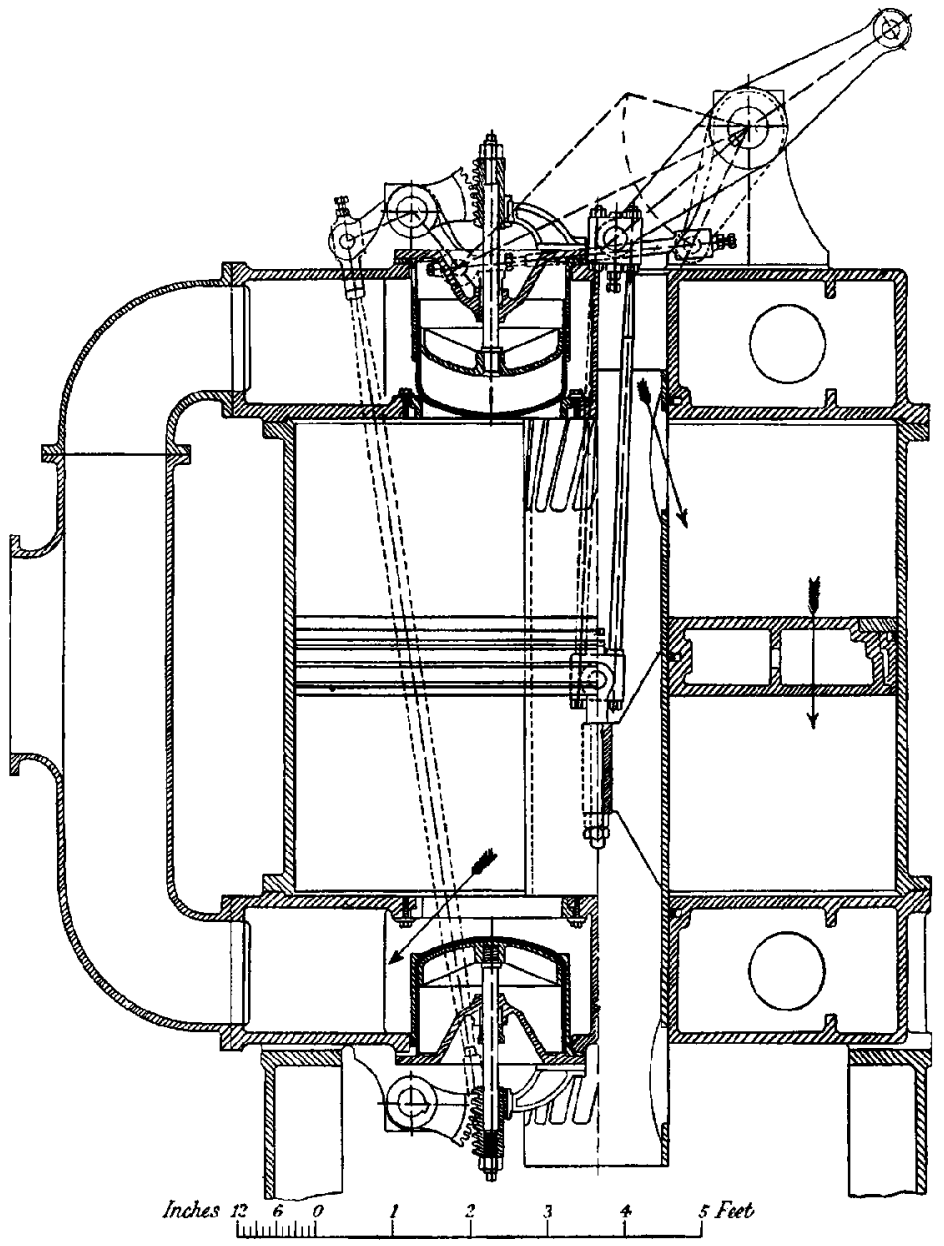

considerable success, running his engine at a piston speed of 600 feet a minute without shock. The serious amount of friction, however, between the valve and its face led him to consider another 
Fis. 4.-Riedler Valves.

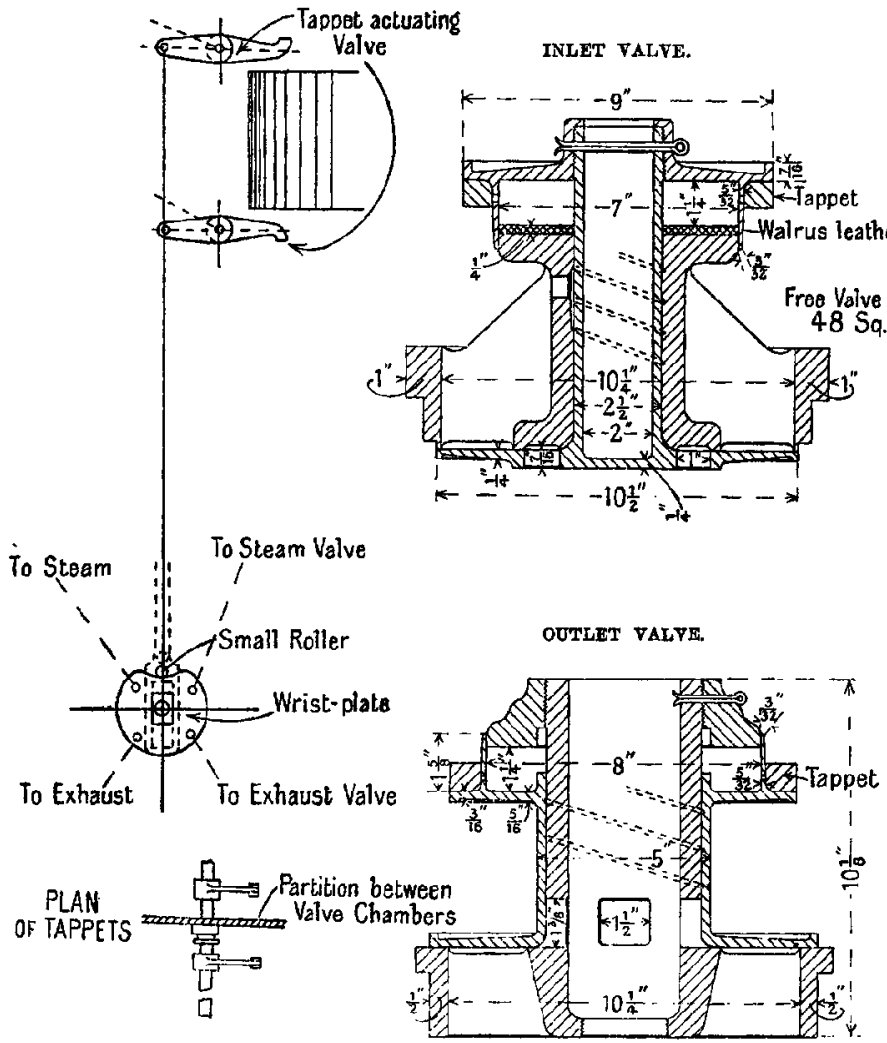

type. He conceived the idea of constructing a cylinder having an annular valve ombracing the cylinder like a sleeve, and sliding upon it. It was operated through special gearing from eccentrics upon the engine crankshaft. This arrangement he patented, and in 1853 several engines were built upon this design. It may be mentioned in passing that a modification of this arrangement was adopted with success a few years ago by Mr. Edward Slick in America, for use in compressors, and the design is now being applied to furnace blowing-engines. 
Probably the next step in this direction was the introduction of the ordinary piston-valve in the well-known Bessemer blowingengine of Daniel Adamson about the year 1870. This engine, as is well known, worked, upon the whole, satisfactorily. When, however, one valve is nsed for both inlet and ontlet, it is almost impossible to fix upon a combination of port width, lap of valve, stroke, etc., that will give the best conditions for both the incoming and outgoing air. Taking into consideration this difficulty, the next step in advance was one of considerable importance. It was the provision of separate and distinct inlet and ontlet valves, each operated by independent mechanism. There are several examples of this latter improvement now in everyday use, and a brief description with sketch is given of a fow of the best known.

Fig. 3 (page 377) shows the Kennedy-Reynolds gear. The inlet or Kennedy valve is a hollow cast-iron tube passing through the centre of cylinder. The outlet or Reynolds valve is cup-shaped, of thin steel plate, and is floating. It is positively closed by an internal plunger, but is free to open automatically. This gear is well known in America, and gives good results. The trunk valve is somewhat objectionable, and will allow some leakage, cause rubbing friction, and it necessitates the use of two piston-rods.

Fig. 4 (page 378) shows the Riedler ralve, as used in compressors, which is fairly woll known in this country, espocially in dealing with high pressures, and has been subject to severe tests at high speeds. The inlet and outlet valves are large in diameter, have narrow beats, and the minimum of air-friction. Their operating mechanism gives splendid control, and is capable of easy adjustment.

Fig. 5 (page 380) shows the Southwark valve, which is also becoming well known. It is composed of grid-iron shaped slides, which move upon the top and bottom covers. They are so designed that there is little rubbing friction because the valve is slightly lifted from its seat by the air at the instant of moving. The clesrance space too is reduced to a minimum. The valve gives a large opening with small travel. The early form of this type of valve, still in use in the United States upon horizontal engines, instead of being made rectangular and sliding straight across the cylinder-head was 
Frg, 5.-Southwark Valve.

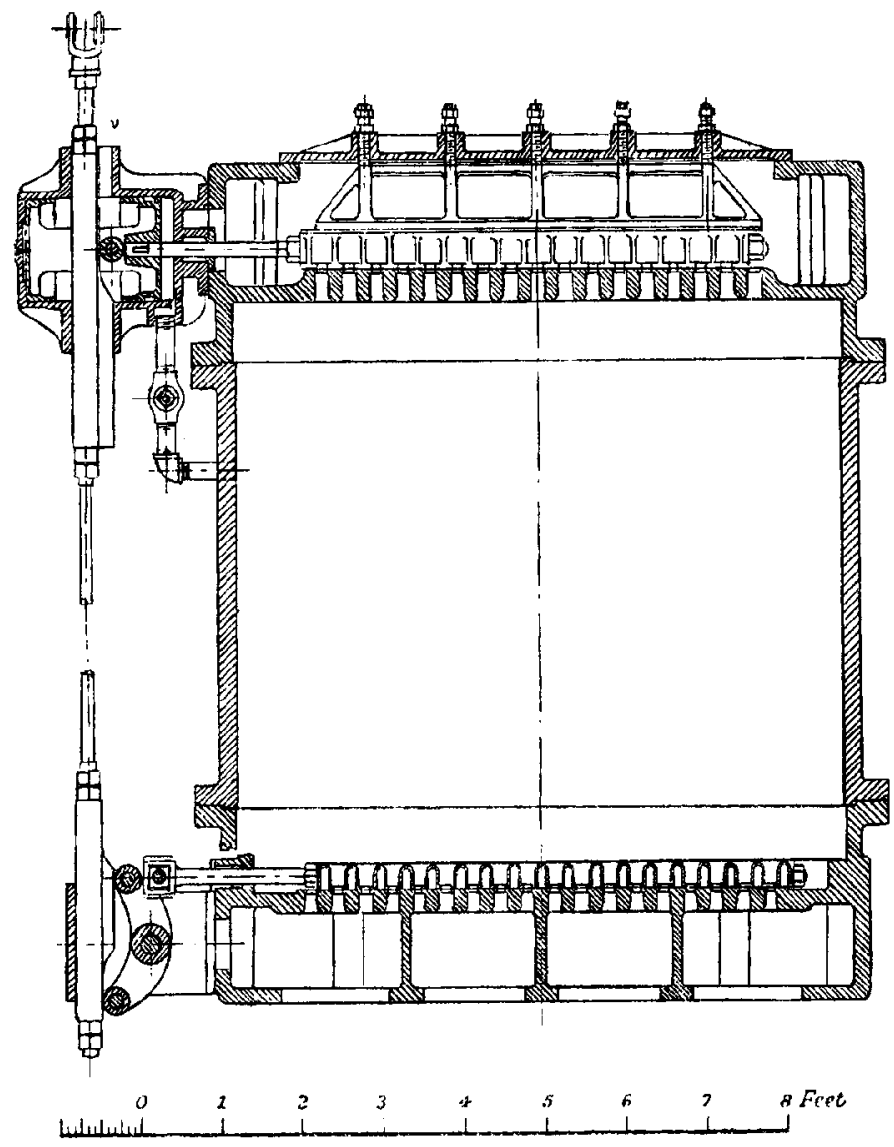

made fan-shaped, and rotated backwards and forwards around the rod.

The Slick valve-gear, as described to the author, is applied to horizontal engines, and is peculiar from the fact that the air-cylinder itself is given a certain amount of reciprocating motion. The 
cylinder-heads are stationary, and are bolted securely to the enginebedding, and they embrace with a working fit the barrel portion of the air-cylinder. This latter has, near each end of it, an annular port which is the inlet for the air, and this port is covered and uncovered as the barrel moves into and out of the cylinder-heads. The outletvalves are merely spring-lcaded dises arranged upon the two stationary hends. The advantage claimed for this cylinder is that it can be effectively filled with free air when running at excessive speeds. In some engines the air on its way to the cylinder coming into contact with the heated surfaces of the inlet-valve and port is thereby expanded, and the above difficulty results at high speeds, and is slightly intensified with valves which split up the flow into a number of small streams. In the case of the Slick valve this failing certainly is reduced to a minimum, for the air has only to find its way through a port, the length of which is but the thickness of working barrel, and which is exposed around its circumference to the cooling action of the atmosphere. The disadvantage of this engine appears to be the large amount of power that must necessarily be required to give motion to the working barrel.

While for the higher pressures and speeds some one of the positive valve movements described above may be necessary, yet for the lower pressures of say 8 or $10 \mathrm{lbs}$. it is quite open to argument whether automatic valves are not almost equally effective.

Positive valves discount some of their advantages by their cost and upkeep, their complication and danger of breakdown, the accurate adjustment necessary, and the power required to drive them. There are many excellent examples of engines giving high efficiency and fair speeds, using automatic valves as still built by some of our best English makers. It has been authoritatively stated that cards from blowing-cylinders show that makers are rapidly approaching theoretical perfection in their construction. While this is to an extent true, it does not necessarily result that, because compression follows the isothermal line, the oylinder is doing excellent work. This will sometimes be found upon investigation to be due to the fact that the cylinder has not been properly filled with air, or may result from leakage during 
compression. In that way an excellent-looking card may be sometimes misleading.

General Arrangement.-With regard to the general arrangement of the cylinders, framings, etc., of blowing-engines; while, as pointed out, the earliest stage was probably some system of tub connected to a water-wheel, considerable influence was exerted upon this, as upon all other designs of engines, by the perfecting of the steam-engine by Watt in the latter end of the eighteenth century.

The first practical design of steam blowing-engine was of the beam type, and that particular type has done good service ever since, and today will be found in some of our older works still usefully employed. A good xample is still to be seen working at Dowlais. This engine has a blowing-cylinder 12 feet diameter by 12 feet stroke. It was built in 1855 , and was described by Mr. Menelaus before this Institution.* It ran through the period of his regime at Dowlais, and also through that of his successor, the President, Mr. Martin, and is still running under the present management of Mr. William Evans. It has been engaged partly in blowing a furnace that has been at work regularly and without intermission for the last twenty-six years, and is still working. The furnace has made up to the present well over three-quarters of a million tons of pig-iron upon its existing lining.

Another interesting blowing-engine, or rather combination of blowing-engines, existed at Dowlais until a few years ago. This was a triple-expansion arrangement, and Fig. 6 is produced from the old drawings of it. It was put to work about 76 years ago, and was probably an example of working expansively in separate cylinders which ante-dated by some years the general introduction of the system.

Although the beam type of engine was justly popular for many years, yet as the demands for higher air-pressures and greater speeds arose, there was a tendency to more directness of design than was obtainable through the medium of a beam, and although engines of

* Proceedings 1857, page 112. 
Fig. 6.-Old Dowlais Blowing-engine, about 1830.

Triple-expansion arraugement.
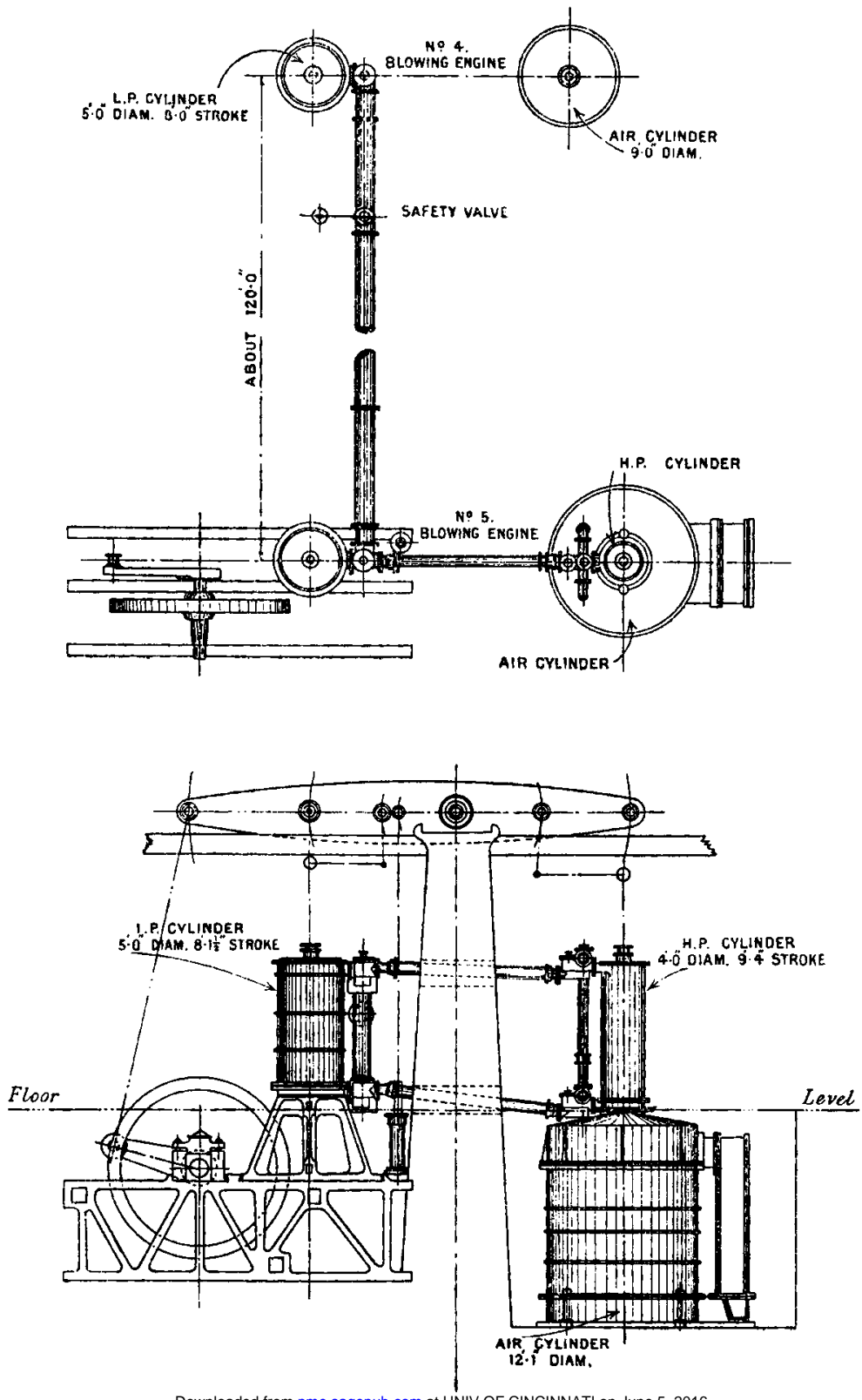

Downloaded from pme.sagepub.com at UNIV OF CINCINNATI on June 5, 2016 
many varieties have been built, in the process of time the "steeple" type has been evolved, and has become almost a standard.

One recent well-known modification, to give a shorter and sturdier engine and thus prevent vibration at high speeds, is what is called the quarter-crank system. In an ordinary steeplo-engine one entire deck of cylinders is, so to speak, planted adjacently upon a separate and independent pair of standards. This system has advantages in the way of facilitating repairs to pistons and rods, and in preventing stoppage of the whole engine from the break-down of one portion. Also, owing to the relative crank displacement adopted, the loads in the steam- and air-cylinders are better timed and balanced, and an even turning moment results. The disadvantage of the system is that all stress goes through the crankshaft, none direct; and the engine takes up a great deal of room.

Two other developments of recent times are the blast-furnace gas blowing-engine and the turbo-blower.

Gas-Engines.-It was in 1894 that attention began to be attracted to the use of blast-furnace gas in gas-engines, and the following year saw its first application at Wishaw for the purpose of driving a dynamo. Since then large sizes have been made, and recently numbers have been applied to blowing purposes, some in England, more on the Continent. American steel-makers also, although, with the exception of one or two not very fortunate examples, they have held aloof from this departure for some time, are now proceeding to adopt them in considerable numbers. There are many types of such engines, both two-cycle and four-cycle, each with its special advantages and disadvantages; but as these have formed the subject of several recent papers it is not proposed to consider them at length here. Without doubt, something like four times the actual work can be got out of furnace-gas when used through a gas-engine as compared with the ordinary method of using it, namely, under boilers; and in the future the gas-engine should have no real competitor for blast-furnace blowing. The upkeep of gas-engines in this country is however at present heary, repairs costly, and lubrication excessive, the running cost of water-cooling, 
and gas-cleaning plant high, as also is the first cost. Gas-cleaning has always been one of the standing troubles with gas-engine work. It can, however, now be effectually done by rotary washers, of which there are several good designs in use that reduce the quantity of dust to a negligible amount.

It is estimated that, by using gas direct in blowing-engines, about 30 per cent. of the total gas given off the furnace will be available outside the plant itself, and where the same is marketable it should form a valuable asset. Upon a modern plant making 2,000 tons a week the spare power should amount to about 1,000 horse-power continuously. Irrespective of the troubles mentioned earlier, this saving will probably bring the gas-engine into general use for blowing purposes in the future. Greater experience and improved design will doubtless make these engines just as reliable as the emall gas-engine in everyday use, which, as is well known, runs over long periods satisfactorily with little attention.

Turbines.-The turbine, though not so economieal as the gasengine, and, due to the eddying effects of steam, no more economical than a high-class steam-engine, nevertheless has many advantages. Its first cost is less than for a reciprocating engine of equivalent power. It takes very little room, and the ontlay upon house and foundation is small. $\Delta$ point of value in the turbine, and one perhaps not generally recognised and appreciated, is the absolute steadiness of the flow of air. This is an important point, and some furnace managers attribute to it considerable improvement in the working of their furnaces. From the earliest times steadiness of the air has been aimed at by the use of large mains, reservoirs, loaded pistons, water-regulators, etc., but it is only perfectly obtained in the turbine-blower. The running cost is very slight, there is practically no friction, and a very small, oil bill, and the oil that is used need not be chosen with that care which is necessary with oil to be put into the cylinders of an ordinary engine. There is also the adventage of an oil-less exhaust for condensing.

With regard to steam economy, in ordinary engines live steam is continually thrown against surfaces just cooled by the exhaust, and 
in older engines, with ports common to both inlet and outlet, the resulting loss is intensified. In turbines the steam is brought into contact with metal approximately the same temperature as itself. Then again there is a certain amount of leakage always taking place past the working valves of a steam-engine, which amount has been recently set down as somewhat excessive. Losses that have in past years been attributed to condensation are now stated by experimenters to bo largely due to leakage past the cylindervalves. The only leakage that can take place in the turbine is that going on through the blades.

Summary.-It is not easy to state or even suggest general rules for the choice of a blast-furnace blowing-engine. Sets of conditions can be found to which the ordinary steam reciprocating blowingengine is best suited, and this is also true with regard to the gas-engine and the turbine. If the surplus gas from any given plant is in great demand, and can be used effectively on the spot, then gas-engines have a great claim to consideration. On the other hand, there is probably no special advantage to be gained if this surplus gas cannot be so dealt with, although there are cases where tho surplus gas is beneficially used for generation of electric power, the sale of which is a set-off to the working cost of the furnaces. It is hardly, under any circumstances, wise to apply gas-ongines to an isolated furnace, unless the expense of a gasometer and producers is permitted.

For augmenting the blowing power of an existing plant the turbine will be found well suited, and in many instances it can be applied without need of any further accommodation than the spare room frequently to be found inside many existing engine-houses. The turbine in combination with ordiuary reciprocating steamengines provides a system both safe and satisfactory, and one that is in many ways ideal; for if there is one weak feature in the turbine it is that of not being quite a "positive" blower, and there is also a slight falling away in volume and efficiency when the pressure increases above the "normal," as results from a "standing" furnace. 
A point about blowing-engines, which possibly does not receive the attention it should, is the correct ratio between the areas of the steam and blowing-cylinders. Each locality from its own conditions of material, such as fineness of ore, hardness of coke, height of furnace, speed of driving, etc., demands a certein normal air-pressure, which it is found prevails almost continually. The pressure will differ somewhat between one district and another. The blowing-engine should be so designed, having regard to the steam supply available, as to be giving its greatest economy when blowing this normal pressure, special arrangements being made, for dealing with the occasional increases of pressure that arise, in steam-engines by retarding the cut-off, and in gas-engines by manipulation of the air inlet-valve, or adjustment of the clearance space. This, however, in the opinion of the author, is not usually the case, and most modern engines will be found so proportioned as to be giving their greatest economy not when working upon the normal pressure but when working at a higher pressure than the normal, and one which occurs only occasionally. In most of the old engines the reverse of this was found, and possibly the constant grievance of the furnace manager, in not being able to obtain his " pillar" (pressure of blast), has in a measure been the cause of this over-reaching movement in the opposite direction.

The Paper is illustrated by 6 Figs. in the letterpress.

\section{Discussion.}

Mr. Josmpr Adamson, in opening the discussion, said that as the author had stated his Paper was historical, he (Mr. Adamson) might be excused for correcting some inaccuracies in it. For instance, it was stated (page 379), "Probably the next step in this direction was the introduction of the ordinary piston-valve in the well-known Bessemer blowing-engine of Daniel Adamson about the jear 1870." He desired to state that Daniel Adamson and Co. made such an 
(Mr. Joseph Adamson.)

engine for Messrs. Platt Brothers in 1859. The engine was of the "steeple" design. The next engine of that kind was built in 1863, and worked very satisfactorily. The 1859 engine made a very great impression on bis mind, and he believed a Paper had been read previously before the Institntion giving the results of some experiments on a solid block-piston. When the engine was designed, it was a debatable point whether the piston should be packed or otherwise. It was decided to put in a solid block-piston, and a turner undertook to bore a cylinder parallel so that a block would fit. The piston was put into the cylinder, and one, then two, and ultimately four grooves were eut in it, and the piston was perfectly tight. The grooves also acted for lubrication purposes. That was the form which was adopted at the present day, excopt when the engineer specified something different. No doubt the members had read of the experiments carried out at Rugby with the solid block-piston. Those experiments were far more exhaustive than Messrs. Daniel Adamson and Co. were then able to carry out, but nevertheless a piston was obtained which was practically tight, and the engines worked perfectly satisfactorily.

Mr. R. H. Hotoninson said that, before offering a few remarks on one of the types of blowing-engines referred to in the Paper, he desired to acknowledge the courtesy which had been extended to him, in that, though not a member of the Institution, he was allowed to be present at and address the meeting. Some of the members present were aware that he was connected with a firm which made the turboblower, to which he desired to refer; and as this might give the impression that his remarks would be somewhat biassed on that account, he would make them less emphatic than otherwise would have been the case. The author mentioned (page 386) that for augmenting the blowing power of an existing plant the turbine would be found well suited. He would not attempt to describe the "Parsons" steam-turbine, hecause he was quite sure that all the members knew more or less about it now; but it might not be out of place to describe briefly the formation of the air-turbine, which was the blower portion. It was really of the same form of construction 
as the steam-turbine, in that it consisted of a cylinder with rows of fixed blades and a revolving drum upon which were placed other rows of blades; the air was simply taken in at one end of the cylinder and compressed through each successivo row of blades, and delivered at the specified pressure at the discharge, so that, as far as its design was concerned, it would be almost impossible to have a machine of simpler construction. There was an entire absence of valves, either of the positive or antomatic kind ; and those who had to use blowing machines would doubtless much appreciate that point.

He was not quite sure whether he rightly understood the author when he remarked (page 386), "The turbine in combination with ordinary reciprocating steam-engines provides a system both safe and satisfactory, and one that is in many ways ideal." He did not know whether that was to be taken as meaning that the turbo-blower was a weak element, and would be fortified by association with the elaborate reciprocating type of engine, or whether it was the other way about. From his point of view he considered the reciprocating system would be strengthened by the introduction of a turbine, and that was partly arrived at because he knew cases where turboblowers had been introduced into existing systems, where the reciprocating blowing plant was sufficient to meet the demand, and reciprocating plant had been eut ont and turbines used regularly instead. On the other hand, it might be asked whether it was desirable to have a turbine installation entirely. The Parsons turboblower was of recent introduction, and where additional blowingplant was required and the turbine was adopted, it was necessarily found in association with reciprocating blowers; but in the case of works intending to lay down entirely new blowing-plant, the question might arise whether it would be safe and desirable to use turbo-blowers only. He was inclined to think, from what the author said in his Paper, that he would reply in the negative. Perhaps the author did not consider that turbines had shown themselves sufficiently reliable to be used except in combination with the reciprocating type of blower, but there were works at the present time which were using turbo-blowers only. Reciprocating types of blowers had been used in such works until the introduction of the 
(Mr, R. H. Hutchinson.)

turbine, when they hrd been cut out and turbo-blowers used entirely, and depended upon. Further, there was now under consideration the installation of a very large blowing-plant, having several units, each capable of dealing with 40,000 cubic feet of free air a minute, with a normal pressure of $10 \mathrm{lbs}$. per square inch, and it was intended to use turbo-blowers entirely.

He was bound to say the anthor had given the turbine a very good character, but there were one or two points in connection with it to which he would like to draw attention. In the first place, Mr. Roberts referred to what might be considered a weak element with the turbo-blower, in that it was not of a positive type. That was true, and without actual running results to fall back upon one would be inclined to withhold any definite expression of opinion on the point, until experience had proved whether it/was the case or not. It had been found, however, that it constituted no weak element at all. That form of blower had been made to work satisfactorily with an air-pressure of $60 \mathrm{lbs}$. per square inch, and higher pressures were contemplated. It might safely be said that the turbo-blower, although not of the positive type, was quite safe and capable of dealing with any demand within its designed range that might be made upon it.

It might be of interest to the members to give some figures in connection with the oil-consumption and the space occupied, both of which points had been referred to in the Paper, because, although they were stated to be less than those in connection with the reciprocating type of blower, some definite figures would establish the point better. The oil-consumption was, of course, very much less with the turbo than with the reciprocating type of blower, none being used in either the air- or steam-cylinders. Oil was required for Inbricating the bearings, and that was supplied under pressure by a pump worked off the turbine shaft, at a pressure of about 5 lbs. per square inch, and was circulated round and round, so that the consumption was practically nil. It had been ascertained, from figures which had been supplied by users of turbo-blowers, that for a machine of about 1,300 or 1,400 HP. the consumption per week of seven days came out at about 1s. $6 d$. to 1s. $9 d$., aud taking the oil 
at $3 s .6 d$ a gallon, this meant that roughly about half a gallon of oil was used per week.

With regard to the space occupied, the author had said it was much less than with reciprocating engines, and that in most cases where there were engine-rooms with the reciprocating type of ongine, a turbine could be easily installed. That was very true, and in nearly all the cases where turbo-blowers were, or were about to be, installed no new buildings had been required. He had one case in mind where a turbine was working alongside a reciprocating engine, and where, considering floor-space only, it would be easily possible to instal four turbo sets as against two reciprocating sets, the capacity of each set being the same. Manufacturers who were considering the question of laying down fresh installations would find that, with the turbo-blower, the cost of the engine-house and the foundations was relatively very small.

The author said that, as regards efficieney, the turbine was not more economical than a high-class steam-engine. With that remark he did not think he could agree, because it would be found, with machines of normal size, that the steam-consumption with a condensing type of turbine would be less than that of the best reciprocating blowers. With regard to the efficiency of the air portion, when extra pressure was required the efficienoy was not quite so good as at normal pressure. The author had rightly drawn attention to the question of maximum efficiency (page 387), where he said that the modern reciprocating types of engines were designed to give their best results when moeting with occasional high load. Turbines were designed to give their best economy when dealing with the normal load, and that seemed to him the better way, because the normal load was on for a much greater time than an occasional high load, and a slight fall in efficiency at the latter time was of small account. The method employed with a turbine in obtaining a higher pressure to meet scaffolding in furnaces was to have a bye-pass, by means of which steam was admitted at an intermediate stage in the steam-turbine, so that by this means it was possible to get a pressure, with a machine designed for a normal pressure of $10 \mathrm{lbs}$. per square inch, of about $18 \mathrm{lbs}$ 
(Mr. R. H. Hutchinson.)

per square inch, which was quite enough to meet ordinary requirements.

In conclusion, he desired to say a word in relation to gas-engines using blast-furnace gas. Of course there was no doubt that, if the gases from the furnace could be conveyed to the engine in a cheap, clean and reliable form, such an engine had much to recommend it, but he believed that this was far from being the case at the present time. He spoke on that subject with limited knowledge, and would be glad if others who followed and who had more experience would give the Institution the benefit of it. He knew of cases in this country, however, where blowers, driven by gas-engines using gas from the furnace, had been put in and were not giving satisfaction; in fact, he knew of one case where the owners of the works would be extremely glad to get rid of the gas-driven blower, and wished they had never put it in. As he had previously said, the gas-driven form of blower was, under certain conditions, an economical machine, but the complicated design and the heavy wear and tear were against it. It was not safe to prophesy what would happen in the future, but if some form of internal-combustion turbine was brought out, he thought it might be safely said that the gasreciprocating engine wonld be no real competitor to it.

Mr. Mark Robinson, Member of Council, desired only to remark upon a sentence (page 386), where the anthor said "Losses that have in past years been attributed to condensation are now stated by experimenters to be largely due to leakage past the cylindervalves." A great deal had, no doubt, been written and said to that effect, but the subject was open to great difference of opinion, and many people who had full knowledge of past experiments upon the steam-consumption of rcciprocating engines were very far indeed from agreeing with the views referred to. No doubt there were plenty of engines with very bad leaks past their valves causing heary losses, but the idea that such losses accounted for those hitherto attributed to condensation was, he believed, entirely wrong. Leakage losses, where they existed, were in addition to condensation losses. There were engines in which valve-leakage lose had been 
ascertainod experimentally, and beyond dispute, to he almost negligible, but such engines were not, and could not be, free from condensation losses.

Reference had been made to the steam-consumption of turbines. He could corroborate what Mr. Hutchinson had said, that when a horse-power as high as 1,300 or 1,400 was reached, the turbine, if other conditions were the same, should be more economical, when working condensing, than a good reciprocating engine. At 1,000 H.P., or less than 1,000 H.P., the question was doubtful; he did not think that superior economy had been proved for the turbine at such figures, but at 1,300 or 1,400 H.P. there was no room for doubt about it.

With regard to the turbo-blower, the simplest and easiest way of getting a blast of any sort was by means of a fan, and if it could be obtained from a fan of sufficient pressure and with sufficient economy, he presumed no one would desire to provide a blast in any other way. The claim made for the turbo-blower was in effect that it was a fan which worked with extreme economy, and gave any pressure which could reasonably be required. As the turboblower was practically a number of fans in series, and as its high speed made the desired pressure easily obtainable, it had prima facie grounds for attention to its claim to high economy. If that claim could be established no other difficulty was likely to stand in its way for long, or to check its competition with the blowing-engine.

Mr. J. A. Coomes said he desired to express his appreciation of the author's most interesting Paper, especially as it formed a peg on which to hang a most useful discussion. He believed he was right in saying that there had been no Paper read before the Institution for a considerable number of years dealing exclusively with air-compressors or blowing-engines. It was interesting to note that, in describing the most recent blowing-engine practice, the author gave descriptions of American gears only, because the Riedler gear described was not used to any extent for blowingengines, and even that could not claim Engligh birth. The author 
(Mr. J. A. Coombs.)

went on to say that the piston-valve was introduced by Mr. Daniel Adamson about the year 1870. He had had an opportunity of looking up the records of the late Daniel Adamson, being now engaged in the pneumatio department of Messre. Daniel Adamson and Co., and he found that Mr. Daniel Adamson used a piston-valve for a blowing-engine in the year 1859, or eleven years previously. He had in his possession the original drawing, which he would be pleased to show to the members if they desired to see it. The author further stated that it was almost impossible to fix the combination of port width, lap of valve, ete., which would give the

FIG. 7.

Indicator Card from Blowing-Engine (Adamson).

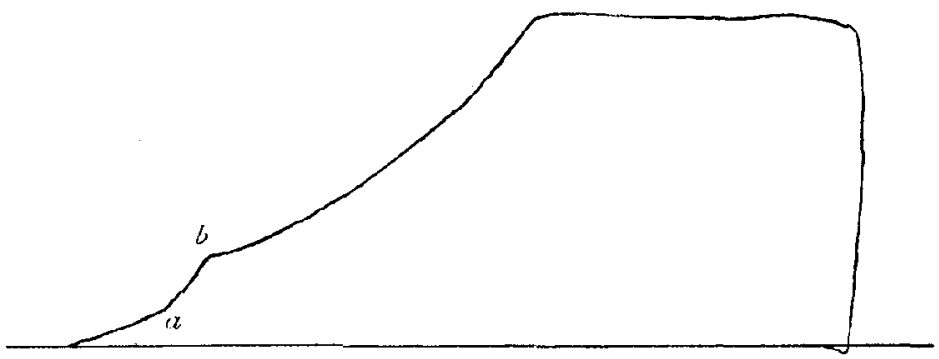

best conditions for bath incoming and outgoing air. Mr. Daniel Adamson fully recognised that, almost with the first engine he made, because it would be found that in 1862 , in the case of a blowing-engine which he made for another firm, he added lift-valves to the delivery passuge beyond the piston-valve, and thus got over the difficulty in a satisfactory manner, as would be seen on examining the indicator card, Fig. 7, which was taken from an engine fitted with the improved gear.

The first engine with piston-valves was made for Messrs. Platt Brothers, of Oldham, in 1859, whereas the first engine fitted with additional lift-valves was made in 1862. Another set was made in 1870 for the Ebbw Vale Steel, Iron and Coal Co., and one pair for the Dowlais Iron Co. in 1871, and that was probably the pair to which the anthor had alluded. Those engines were, he believed, 
still working, and if so he had no doubt they would be on view to the members when they visited the works. Messrs. Daniel Adamson and Co. had made a large number of blowing-ongines fitted with that class of valve-gear in the last forty-six years. For ordinary blast-farnace work, with 7 to $10 \mathrm{lbs}$. per square inch, leather-faced valves were found to work satisfactorily at the speeds then adopted; in fact, quick revolutions on the frames made some twenty years ago would not have been advisable. It would thus be seen that the path of progress had been from the mechanical to the automatic, and Mr. Daniel Adamson's experience of forty years ago was found to agree with Mr. Roberts' dictum, that it was open to argument whether automatic valves were not equally effective with positive movements. He would even go further and say that for alow revolutions they were not warranted, but for quick revolutions they were a necessity in reciprocating engines. Ho personally doubted if Mr. Daniel Adamson would have adopted the mechanicallyoperated valve at all, if the modern light steel annular plate-valves had been evolved. With pressures of 25 lbs. per square inch it must be remembered that the final temperature of compression was $234^{\circ}$ F., or a temperature which would have quickly perished leather or any other soft-faced valve, whereas for $10 \mathrm{lbs}$. per square inch the final temperature was only $145^{\circ} \mathrm{F}$, that was, the theoretical final temperature, not the actual. In the future, with higher piston speeds and revolutions than were now in use, no doubt shorter strokes and quicker revolutions would be adopted, together with smaller diameters for blowing-cylinders, and thus the stage had been reached where mechanically-operated valves were required. He thought that, with triple-expansion sterm-cylinders and triple but simple-blowing cylinders the blast should be practically constant, and thus aroid the objection to reciprocating engines mentioned by the author.

He confessed to a certain amount of disappointment that the Paper had not gone more fully into the development of the various gears described. For instance, the Good gear, or the Southwark as it was now known, dated back to 1888 , and was not therefore a new gear or principle, but had gradually developed alongside 
(Mr. J. A. Coombs.)

automatic-valves. Most of the prominent gears at the present time had taken a long time to develop, and while they had been developing, the automatic- or lift-valves, especially the plate-steel annular valves, had been developing at the same time. He would like to know the limits of epeed of the Southwark gear, that is, the minimum speed at which it paid to instal it in the place of automatic-valves, and the maximum speed at which it would give efficient results. The air-pressure rose so quickly in the blowing cylinder during compression, that in a gear of that description one would expect to find at, say, 90 to 100 revolutions per minute a considerable rise above the blast-pressure in the cylinder itself before the valve opened, and one knew that if the pressure did rise above the blast-pressure it did not drop at once when the valve opened, but caused a considerable loss in extra power required. He would, therefore, have liked to see dirgrams taken at the high and low limits of speed with the same engine.

It would be useful to know the experience of users in reference to the diffioulty of getting at the valve-seats of the Sonthwark gear. For instance, from the illustrations in the Paper he bolieved it was impossible to get at the valve-seats to examine them without dismantling the engine. That would only occur occasionally, but it might cause considerable trouble. He noted that in the first gears in the "steeple" type of engine the blowing-cylinder was arranged immediately on top of the frame, as in standard English practice, but that in the later types those cylinders were ell arranged on top of the steam-cylinders to obviate that difficulty; but oren then the bottom valve-seat could not be got at unless the blowing-cylinder was dismantled. That arrangement not only looked ungainly and top heavy, but it also had the disadvantage of loss in efficiency due to heating of the blowing-cylinder owing to rise of heat convection currents.

At the present moment there was rather a vague idea, in dealing with smaller compressors of high pressure, as to the use of the water-jacket. His own impression was that the water-jacket for compressors was the exact reverse of the steam-jacket for steamcylinders. He took it the most importent point with regard to 
steam-jackets was to provent initial condensation, and so it was with the water-jacket for the air-cylinder; it was to prevent initial heating of the air before it entered the cylinder. Afterwards the water-jacket did not do much more than keep the oylinder-walls cool, and so make lubrication a little better. The time was so short for any cooling to take place, that when it was remembered that for every 5 per cent. rise in temperature of the inlet air it increased the horse-power by 1 per cent., the real reason was arrived at for the water-jacket on the compressor. That was an important point in the higher-pressure compressors, and he took it it was equally important for the blowing engineer to keep the air cool until it got into the blowing-cylinder for compression. He would like to know the air-velocities allowed through the ports of valves in the case of gears of the Southwark type, and also in what fraction of the stroke the valves wore opened and closed, so that the average velocities of air through the ports could be calculated. Some figures as to air-consumptions in blast-furnaces would be extremely useful; also some facts about the raising of the airpressures at English ironworks. He desired to ask, in conclusion, whether, in the author's opinion, they bad to look forward to increased air-pressures, or whether the old pressures of from 7 to 10 lbs. per equare inch were to be the practice in the future for blast-furnace work.

Mr. Exoor J James said he was sometimes asked by his friends to recommend the kind of blowing power that should be adopted, and, being impressed with the turbo-blower, he would like to know the particulars of the coal-consumption per ton of pig-iron made. The partioulars of the oil-consumption had been given by Mr. Hutchinson (page 390), and it would be equally satisfactory if the particulars of the coal-consumption were also given. It might be interesting to young engineers to know that the chief requirements of the blastfurnace was an engine that should go without a breakdown from January to the end of December. He had had a good deal to do with some of the newer kinds of engines, and, speaking not quite as a mechanical engineer, he was grieved over their complications. 
(Mr. Enoch James.)

His one fear with regard to the turbo-blower was that when repairs had to be done they would be costly, and he would be glad of further information on that point. There was another point with regard to the working of the tiubo-blower, namely, when a blastfurnace required blast and there was no gas to supply the steam, where would the engineer get it from for the turbo-engine? An engine with varied powers was required which was able to work at low steam-pressure.

The Prestons, before proposing a vote of thanks to the author for his interesting and instructive Paper, desired to inform their American friends present that the engineers in the South Wales district could not only show them examples of modern experience in the manufacture of iron, steel, mining, and shipping of coal, but could also show them some of the archæology of these trades. The father of Mr. E. Windsor Richards, their Past-President, was the engineer at Dowlais when the triple-expansion arrangement referred to in the Paper was first tried. He simply mentioned that as an interesting historical fact. Fe was sure the members would agree that a hearty vote of thaniss should be accorded to Mr. Roberts for his interesting Paper.

The resolution was carried with acclamation.

Mr. Roberte, in reply, said he regretted he had not been previously aware of Daniel Adamson's earliest application of pistonvalves as cited bs Mr. Joseph Adamson. Had he known of it he would certainly have mentioned it in the Paper. Mr. Adamson's interesting description of piston-grooving was well known to engineors, and when adopted in Adamson's time was no doubt a stop in advance, giving a fairly air-tight piston without the usual rings. He might howerer mention that in practice the system had not been altogether satisfactory, because it was found that the grooves of such pistons, after being in use for some time, filled up solid with lubrication deposit and other matter and thus becamo valueless for the purpose intended. 
Mr. Hutchinson had asked him, in associating the reciprocating engine with the turbine as an ideal combination, which of the two he considered the weak member. He had stated in the Paper that the one weak feature in the turbine sought to be overcome by the suggested combination was tho loss of volume of free air delivercd at pressures exceeding the normal. The turbine, as pointed out by Mr. Mark Robinson (page 393), was merely a number of fans in series, and he (the author) agreed that the fan certainly was "the simplest and easiest way of getting a blast," but it nevertheless could not be called a positive blower. The fan would do good work at the pressure for which it was designed, but it was well known that if that pressure were increased either by contracting the orifice or by other means, the volume and efficiency of the fan was greatly reduced, thongh its speed might be maintained by augmenting the steam end in some manner as that described by Mr. Hutchinson. The conditions prevailing at a blast-furnace plant required that approximately the same quantity of air should be sent through the furnace per minute, irrespective of the furnace's condition and the consequent pressure at the tujeres. It was to assist the turbine at periods of increased pressure and thus keep up the full supply that he (the author) suggested the association with it of a reciprocating engine, and considered the combination a fairly ideal system of blowing. Mr. Hutchinson had stated that there was no difficulty now in providing a turbine that would blow up to 60 or $80 \mathrm{lbs}$. per square inch, and therefore the question of any trouble arising for blast-furnace work at say 10 lbs. need hardly be considered. This argument was however somewhat beside the point. It was admitted that turbines could blow at 60 or $80 \mathrm{lbs}$. when they were specially designed for it; the point contended was that a turbine designed to blow $10 \mathrm{lbs}$. did not in practice satisfactorily drive into the furnace the full supply of air against occasional pressures of 16 or 18 lbs.

Mr. Mark Robinson had stated (page 392) that his (the author's) reference in the Paper to the respective losses of condensation and valve leakages was not correct. All be had to say in reply to that criticism was, that his remarks upon the subject had been taken 
(Mr. David E. Roberts.)

from the findings given in the Report of the Steam-Engine Rescarch Committee of the Institution.*

Mr. Coombs had, together with some interesting drawings, displayed a diagram, Fig. 7 (page 394), which he was quito willing to accept Mr. Coombs' assurance for, had been taken

Fig. 8.

Blowing Cylinder (Adamson).

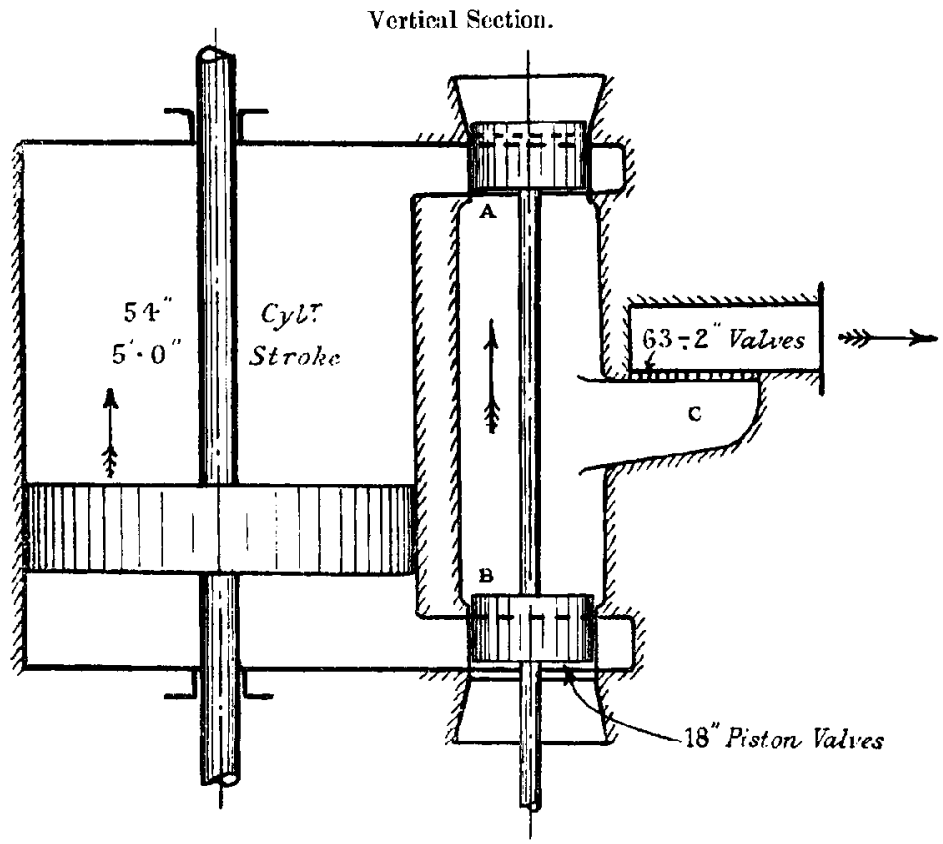

from an Adumson's blowing-engine. It was the typical Adamson blowing-cylinder diagram, the feature of which was the defective hump at the points $a b$, and the reason for this defect was the following:-Fig. 8 showed approximately a vertical section through this blowing cylinder. When the piston had left the bottom end of the cylinder about 10 or 12 inches, as in the

* Proceedings, 1905. Part 2, page 171. 
illustration, the piston-valve began to uncover the upper port at the top end of the cylinder, thus placing the chest $A$ B C and the cylinder proper into communication. The air in chest $A$ B $C$ was at the pressure of the mains, that is, 20 to 25 lbs. per square inch, while the air in the cylinder had been compressed only to about

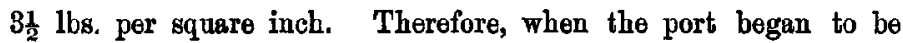
uncovered, the high-pressure air in the chest (which had a capacity of about 12 cubic feet) flowed back into the cylinder (which just then had an effective capacity of about six times that of the chest), and increased the pressure in it from about $3 \frac{1}{2}$ lbs. to about $7 \frac{1}{2}$ lbs. as indicated by the curious hump at $a b$ upon the diagram, Fig. 7 (page 394). The re-compression of this quantity of air, which at full speed amounted to nearly 1,000 cubic feet per minute, meant a rather serious waste of energy.

Mr. Coombs asked a number of questions relating particularly to the Southwark gear (page 396). The author, however, had not intended to give this special gear any greater prominence than any of the other gears mentioned, and therefore he hardly felt justified in taking up the time of the meeting by offering a long detailed account of it. The Paper was merely intended to deal in a very general manner with blast-furnace blowing.

He agreed with Mr. Enoch James that reliability was of first importance in a blowing-engine, and that complications should be avoided wherever possible.

He wished to thank the President for the kind manner in which he had proposed the rote of thanks to himself, and the Members present for their reception of the same. 